warning to us all properly to weigh the evidence both for and against an established and provenly useful treatment before publicly decrying it.

Mevagissey,
St Austell, Cornwall

\section{Treating stroke: home or hospital?}

SIR,-Dr Graham Mulley and Professor T Arie (11 November, p 1321) rightly draw attention to the need to evaluate claims for the effectiveness of stroke rehabilitation in hospital. However, I would challenge their statement that stroke rehabilitation units "make great demands on the health service in both money and staff." It is at least arguable that the demands arise not from the units but from the needs of the severely disabled patients, who require a great deal of care wherever they are located. Indeed, these needs may well be met more economically and more effectively when the patients are grouped in a unit dedicated to multidisciplinary rehabilitation than when they are scattered throughout the hospital.

The 30-bedded stroke rehabilitation ward at Lightburn Hospital, Glasgow, obtained good results ${ }^{1}$ in the rehabilitation of severely disabled stroke patients with no more medical and nursing staff than in the geriatric wards of the hospital and with the part-time services of only two physiotherapists, one occupational therapist, one speech therapist, and one social worker. The costs were less than those of a general medical ward. A similar unit in Edinburgh $^{2}$ is nearing completion of a comparative trial of its effectiveness with that of general medical wards. Many intangible benefits are excluded from such objective assessments, such as the heightened awareness by all grades of staff of the complexity of the patients' needs and the reassurance given to caring relatives by the insight and understanding of the staff. I don't know how one "assesses objectively" whether stroke rehabilitation units "offer good value for money." I would have thought that that requires a subjective judgment; and my view is that if I were myself to suffer a stroke I should prefer to be in a stroke rehabilitation unit.

BERNARD IsAACS

University Department of Medicine, Queen Elizabeth Hospital,

1 Isaacs, B, Health Bulletin, 1977, 35, 94.

Garraway, M, and Akhtar, A J, in Recent Advances in Geriatric Medicine (1) ed B Isaacs, p 7. Edinburgh,

\section{Severe hyponatraemia in hospital inpatients}

SIR,-We were disappointed that in their article on this subject (4 November, p 1251) Dr P G E Kennedy and his colleagues ignore much relevant literature.

We endorse their main conclusions: that the so-called syndrome of inappropriate secretion antidiuretic hormone is not a common cause of severe hyponatraemia, that there is rarely any need to restrict water intake, and that urine analysis is of little practical value. Flear and Singh ${ }^{1}$ said the same and also showed hyponatraemia to be common in a variety of clinical conditions, its incidence and extent varying with the severity of the illness. They showed that an abrupt fall in sodium con- centration was often caused by a widespread increase in membrane permeability.

Membrane permeability is increased by many factors: hypoxia, increased catecholamines, viral infection, endotoxins, and malnutrition. As a result of such an increase some normally non-diffusible solutes "leak" from cells, taking with them water. The resulting hyponatraemia persists for as long as these solutes remain in the extracellular fluid ${ }^{2}$ and during this time the abnormality is reflected in an increase in the ratio between osmolality (corrected for urea and glucose) and plasma sodium concentration. At the same time cells tend to gain sodium despite increased "sodium pump" activity. This gain accounts for the net fall in extracellular volume usually seen but does not lower the concentration of sodium. ${ }^{2}$ : Hyponatraemia may also develop insidiously when cells show a sustained inability to maintain, by metabolic activity, their normal quantity of non-diffusible solutes

Dr Kennedy and his colleagues ignore these possibilities. We suggest that the so-called "sick cell syndrome" was probably a factor in most of their 44 cases and may entirely explain their four "severely ill" patients in whom hyponatraemia had "no recognised cause."

Hyponatraemia due to either of the cell causes outlined (abrupt or insidious) reflects the severity of the illness and impending threat to renal, cerebral, and myocardial function. In neither situation is hyponatraemia itself dangerous. Indeed, it may be helpful. Lowering the plasma sodium level reduces the rate at which sodium ions enter cells and lessens the electrochemical gradient against which "sodium pumps" have to operate. Both effects limit the rise in cellular energy expenditure observed in the critically ill. ${ }^{4}$ The therapeutic use of saline solutions in such situations may overwhelm the sodium pumps, causing sodium to accumulate rapidly in cells and thus further impairing tissue function. Dextran 70 is a preferable volume expander. Insulin reduces cell membrane permeability to sodium and facilitates "sodium pump" activity. Infused with glucose, it has reversed hyponatraemia in burns, ${ }^{5}$ trauma ${ }^{6}$ heart failure, ${ }^{7}$ and fulminant hepatic failure. ${ }^{8}$

Cecil T G Flear J BURN

University Department of Clinical Biochemistry and
Royal Victoria Infirmary, Royal Victoria Infirm
Newcastle upon Tyne

${ }^{1}$ Flear, C T G, and Singh, C M, British fournal of Anaesthesia, 1973, 45, 976.

Flear, C T G, Lancet, 1974, 2, 164

Leaf, A, Lancet, 1974, 1, 119

Flear, C T G, Bhattacharya, S S, and Nandra, G S, in
Nutritional Aspects of the Critically Ill, ed J Nutritional Aspects of the Critically Ill, ed J R Churchill Livingstone, 1977 .

Hinton, P, et al, Lancet, 1973, 2, 218

Woolfson, A M J, Heatley, R V, and Allison, S P, in Nutritional Aspects of the Critically Ill, ed $\mathrm{J} \mathrm{R}$ Richards and J M Kinney, p 367 . Edinburgh, Churchill Livingstone, 1977.

' Majid, P A, et al, Lancet, 1972, 2, 937.
' Burn, J, and Williams, W D C, Intensive Care Medicine, 1978, 4, 133 .

SIR,-The report of Dr P G E Kennedy and others (4 November, p 1251) on their patients with plasma sodium concentrations below $125 \mathrm{mmol} / 1$ cannot go without comment with regard to their conclusion that "analysis of blood and urine was of no value in distinguishing the different diagnostic groups in an emergency."

Firstly, only the results of estimations of urinary sodium concentration and urine osmolality are shown and even then we are not told whether these were made on spot or timed urinary collections. Urinary sodium concentrations and osmolalities are dependent on many factors and a very wide range of values occurs even in the normal individual. If the authors had hoped to be able to distinguish "depletional" from "dilutional" causes of hyponatraemia using these measurements alone, then they predictably did not obtain what they expected. Previous studies ${ }^{1}$ have shown that in assessing hyponatraemia biochemical results are much more meaningful if comparisons of urine and plasma osmolality are made. In the second of the studies cited," for example, the patients were all in the "dilutional" group of hyponatraemics and showed marked variation of urinary sodium concentrations and osmolalities, yet the results became much more meaningful when plasma and urine osmolalities were compared.

Secondly, the authors include in their "depletional" group of hyponatraemics all the patients on diuretics. It has been reported" that patients on thiazides or frusamide have increased levels of circulating antidiuretic hormone $(\mathrm{ADH})$ in the presence of a low plasma osmolality and may therefore have "dilution" as a cause of hyponatraemia. Only in three of their eight patients on diuretics was there clinical evidence of dehydration, so on what other evidence the authors placed this whole group of patients in the "depletional" category of hyponatraemia is unclear.

Thirdly, it is also unclear what the authors mean by "emergencies"-whether the emergency was due to hyponatraemia per se or whether the hyponatraemia was an epiphenomenon in otherwise critically ill patients. The authors state that "although 12 deaths occurred among the 44 patients hyponatraemia did not play a part in any."

As a result of widespread use of biochemical screening hyponatraemia of varying severity remains a commonly encountered biochemical abnormality. Infrequently hyponatraemia results in encephalopathy and, as the results of other studies ${ }^{2}$ is have shown, correct therapeutic intervention on the basis of analysing the most appropriate biochemical parameters -namely, comparison of plasma and urine osmolalities, on spot samples initially and on a 24-h urine specimen later, and plasma ADH levels when available-has often led to the reversal of cerebral problems.

As they have used inappropriate biochemical parameters in their ill-defined clinical context of "emergencies" Dr Kennedy and his colleagues cannot be justified in their final conclusion.

Department of Biochemical

$S$ JAVED IQBAL P J OJWANG

Medicine

Ninewells Hospital,

1 Thomas, T H, et al, Lancet, 1978, 1, 621.

De Trayner, A, and Domenet, J C, Quarterly fournal of Medicine, 1976, 45, 521 .

17, 1.
Ashton, M G, et al, British Medical fournal, 1977, 1,

${ }^{5}$ Ruby, R J, and Burton, J R, Lancet, 1977, 1, 1212.

\section{Dexamethasone in acute stroke}

SIR,-In a recent article by Dr Graham Mulley and others (7 October, p 994) and subsequent discussion there has been no reference to the interval between the onset of stroke and the 